\title{
ADVANCES IN PEDIATRICS
}

\section{Children and Megadisasters: Lessons Learned in the New Millennium}

\author{
Andrew L. Garrett, MD, MPH ${ }^{\mathrm{a}, *}$, Roy Grant, $\mathrm{MA}^{\mathrm{b}}$, \\ Paula Madrid, PsyD ${ }^{\mathrm{a}}$, Arturo Brito, MD, $\mathrm{MPH}^{\mathrm{b}}$, \\ David Abramson, $\mathrm{PhD}, \mathrm{MPH}^{\mathrm{a}}$, Irwin Redlener, $\mathrm{MD}^{\mathrm{a}}$ \\ ${ }^{a}$ National Center for Disaster Preparedness, Columbia University, Mailman School of Public \\ Health, 722 W. 168th St., New York, NY 10023, USA \\ ${ }^{\text {b} C h i l d r e n ' s ~ H e a l t h ~ F u n d, ~} 215$ West 125th Street, Suite 301, New York, NY 10027, USA
}

$\mathrm{T}$

he term megadisaster has worked its way into the mainstream since the start of the new millennium. The expression once reserved for the technical meaning of the word-a "one in a million" disaster-has recently been brought to the forefront by several large natural events that have occurred in the past 5 years, namely Hurricane Katrina in the United States and the Indian Ocean tsunami of 2004. These two disasters, as well as the terrorist attacks of September 2001 in the United States have directed a persistent spotlight on the systems by which the public and its government plan for, respond to, and recover from high-impact catastrophes.

From the beginnings of human society, both nature and our own species have found ways to traumatically disrupt the status quo. Despite the many catastrophes in our history, the term disaster has been difficult to define. Most definitions include some reference to the event's impact on people, the economy, or the environment. More theoretically, a disaster can be seen as a complex function of risk and vulnerability. As an example, the magnitude of a hurricane disaster is not as simple as the force of the hurricane itself upon a community but rather a sum of those forces (eg, storm-force winds) plus the special vulnerabilities faced by the community (eg, levee failure) plus the community's capacity to reduce the actual or potential negative consequences of risk (eg, an inability to evacuate citizens). It is complicated interplay among the forces of destruction and the broad ability (or inability) of a community, for myriad reasons, to withstand them and mitigate their impact.

There is ranging opinion and there has been much discussion about the practical definition of disaster, much of it dependent upon the context in which the term is being analyzed. Many academics feel that for an incident to be technically classified as a disaster, it must overwhelm the day-to-day routine enough

*Corresponding author. E-mail address: ag2612@columbia.edu (A.L. Garrett). 
so much that those who are affected must alter their behavior and reach outside of their normal support structure for assistance that would normally come from within their own community. The layperson, however, has a less restrictive definition and typically describes a disaster as any incident that causes a significant loss of life or property damage. Although there is clearly a continuum between a crisis, a disaster, and a megadisaster, experts disagree as to where the demarcations lie, and the basis for making these distinctions. The situations discussed in this article are clearly at the megadisaster end of this spectrum and, for our purposes, they meet the criteria discussed in Redlener's book on the subject: an emergency that overwhelms local and regional response capacity and includes such factors as an inability to manage rescue and medical needs, a failure to protect vital infrastructure, and a degree of uncontrolled societal breakdown [1].

Hurricane Katrina is America's most recent encounter with a megadisaster. But what made it a megadisaster instead of just another category 3 hurricane of the type that seasonally exists in the Gulf of Mexico? Katrina was not the largest or strongest hurricane to strike the United States mainland in the recent past, but its effects were devastating and wide reaching beyond our wildest nightmares, far beyond those of Hurricane Andrew (1992), a category 5 hurricane that scoured much of Florida and the Gulf Coast. Hurricane Katrina's track directly targeted gaping vulnerabilities in infrastructure and society, and set in motion a series of events that culminated in the deaths of nearly 2000 people, resulted in hundreds of missing individuals, and caused a potential economic impact of up to $\$ 150$ billion. The disruption of people's lives was immeasurable, as was the impact on the long-term physical and mental health of the victims, which continues today. Katrina also led to a substantial decline in the confidence that the public has in its government to provide essential services during a disaster.

The year 2001 was a terrible beginning to a millennium that had transitioned uneventfully. Having just dodged the "Y2K" bullet, which many feared would unravel the fabric of society, most Americans went about their lives completely unaware of their susceptibility to terrorism. The nation suddenly entered a new era of vulnerability and fear as thousands died in New York City, Washington, D.C., and Shanksville, Pennsylvania, at the hands of extreme jihadists. Shortly thereafter, a handful of letters tainted with anthrax ushered in the first widespread biological attack that the nation had experienced. Despite the low casualty count, the letters led to a massive disruption of the US Postal Service infrastructure and cost hundreds of millions of dollars to remediate. After extensive investigation, the crime remains unsolved, leaving many to wonder if it could happen again. These events had wide-reaching aftershocks as the nation returned to war and scrambled to improve the nation's disaster and terrorism detection, response, and recovery infrastructure at an unprecedented cost to the public. The megadisaster of the 2001 terrorist attacks on the United States continues to claim casualties and astronomical costs 6 years later and has affected every person in the United States in one way or another. 
Children are among the most susceptible members of a community when catastrophes such as these strike because of their dependent nature as well as their physiologic and psychological vulnerability. Children affected by Katrina were no exception. Persistent critical gaps exist in the ability to prepare for and respond to the needs of the youngest victims. These were clearly exposed as children endured an at times ineffectual disaster response followed by a stressful recovery that is still ongoing. An analysis of the issues that faced children during this event and some others from the recent past may help society reduce the impact of such disasters on children in the future. This article focuses on a few of the major shortfalls in the care of children that have become especially apparent in the last few years:

\section{Facilitating evacuation}

Providing shelter

Caring for those with special medical needs

Addressing mental health needs

These scenarios are not new. Historical accounts of the aftermath of the 1906 San Francisco Earthquake depict a scene that mirrors that following Hurricane Katrina-with widespread suffering; overworked and overwhelmed public services, such as law enforcement and hospital care; and inadequate public relief in the form of food, water, and shelter. As some who have studied this megadisaster observed, "society's ability to respond to major disasters seems to have progressed little in the century" [2].

Future disasters will predictably overwhelm the public and those who work to maintain health, safety, and lawfulness in society. No amount of prevention and mitigation will ever fully eliminate the burden of large-scale disasters. That said, it is entirely realistic to set achievable goals that may significantly reduce preventable suffering and ensure equity for all affected individuals preparing for, responding to, and recovering from a disaster. These goals are best accomplished by learning from past experiences, both distant and recent, studying new preparedness and response strategies, and taking purposeful action when indicated.

\section{CRITICAL RESPONSE AND RECOVERY ISSUES}

\section{Evacuation}

During and after Hurricane Katrina, children were especially vulnerable to harm from the disorderly evacuation and chaos that followed in New Orleans after the levees broke and the city flooded. Estimates are that $80 \%$ of the population of the city relocated ahead of the storm, with approximately 25,000 using a "refuge of last resort," the city's Louisiana Superdome [3]. Many rode the storm out in their homes. With an immense population on the move and the remainder in areas with conditions that would quickly deteriorate, many of the children involved in the evacuation soon faced struggles that would range from a shortage of shelter, food, water, and chronic medical care to an imminent threat to their lives as their homes were overtaken by floodwaters. Heroic efforts by the military, the US Coast Guard, authorities, 
and the public resulted in the rescue of tens of thousands who would likely have perished. Local, state, and federal officials, as well as volunteers, worked tirelessly but haphazardly to provide rescue and relief under oppressive conditions. Many children were removed from harm's way and delivered to shelters or evacuation waystations, such as the city's Louis Armstrong Airport, with few initial physical casualties. During the first days of the storm and the subsequent evacuations, nearly 5000 children were reported missing. Eventually, nearly all of the children were reunited with their caregivers. In some cases, however, this process took up to 2 months. Many children endured frightening experiences. One third of surveyed fourth to twelfth graders in the region reported that they were separated from their caregivers during or after the storm. An additional one third reported being separated from a family pet. One in five reported an injury to a family member, and 15\% said that a family member had died [4].

Just a few weeks after Hurricane Katrina struck New Orleans, Hurricane Rita threatened the Gulf Coast. The hurricane's path would likely bring the storm through Houston. Motivated by fears of another Katrina-like catastrophe, 2.5 million people evacuated the region. Ninety of the 111 storm-related deaths in this instance were due to the evacuation process itself as gridlock on the highway and oppressive heat took its toll on the chronically ill and elderly. Several complicated issues emerged as factors affecting the process of evacuation.

\section{Barriers to preparedness}

A national survey conducted in 2006 by the National Center for Disaster Preparedness demonstrated that only a minority of the American public is personally prepared for a disaster [5]. Less than one third (31\%) have made basic family emergency preparations, which means planning on a meeting place and having at hand at least a 2-day supply of food and water, a flashlight, a portable radio, spare batteries, and emergency phone numbers. In terms of attitude, two-thirds $(66 \%)$ feel personally unprepared. These figures are virtually unchanged from 2005 (31\% and 64\%, respectively).

During and after Hurricane Katrina, some children were unavoidably separated from families during the rescue process, and others may not have been with their families when the storm made further travel impossible. Still, a general lack of disaster preparedness by individuals and families likely contributed to the large initial number of missing children. Without a mechanism for all members of a family to reconnect, such as via an out-of-area contact, it can take days, weeks, or longer for such agencies as the American Red Cross and the National Center for Missing and Exploited Children to reconnect separated people. Asked why they do not have a family emergency preparedness plan, a quarter of those surveyed $(26 \%)$ say they have not had enough time to assemble these items with nearly another quarter $(22 \%)$ saying they do not know what to do to achieve basic preparedness. Only 3\% report that they already feel prepared. The percentages for these reasons are virtually unchanged 
since 2005. These findings strongly suggest that despite recent well-funded and well-intended efforts by government emergency officials and employers, risk communication has failed to convince the American public that family disaster preparedness is essential.

A community evacuation plan that engages all citizens and accounts for their needs is an essential element of community preparedness. As was made apparent in New Orleans, the government must direct and facilitate the movement of individuals out of harm's way to the extent possible. However, the cooperation of those citizens who would be required to evacuate is also crucial. Moving people to safety in an orderly fashion during an emergency has been and can be expected to continue to be problematic. Lack of personal or public transportation and concerns about the welfare of dependents are daunting barriers to effective community evacuation, as was demonstrated in New Orleans. Surveys reveal that $29 \%$ of respondents cite lack of access to transportation as a reason that they would be unable to evacuate when ordered to by authorities, a figure virtually identical to responses in 2005 (30\%). An overwhelming 92\% of Americans have at least one reason why they would not evacuate immediately if ordered to do so. This is unchanged since 2005. The most common reasons cited are the need to ensure the safety of dependent family members-children $(48 \%)$, elderly (47\%), disabled (45\%), and pets (34\%) [5].

The same study also indicates a low level of confidence in the government to be able to provide essential disaster services to the community. After Hurricane Katrina, fewer than half of the residents in the Gulf Region are confident in the ability of government to respond appropriately to a natural disaster (47\%). In 2006 , only half of those questioned in a national poll felt that their government had adequate plans in place to respond to a natural disaster. This was unchanged from 2005, pre-Katrina. The number of those who said they would resist a mandatory evacuation order increased in 2006 to $42 \%$, up from $36 \%$ the year before [5]. These data suggest that there is a critical shortfall in the engagement of individuals and families to become partners with government agencies that are supposed to protect them, and vice versa. As seen in New Orleans during Hurricane Katrina, a disconnect between emergency messaging by authorities and public response likely contributed to poor decision-making by many in the community as the threat from the storm increased and time ran out to evacuate. This led to a drastically unstable scenario that risked the lives of tens of thousands of victims, and generated an immense demand on the government to conduct dangerous, costly, and labor-intensive rescue and relief operations. The challenging logistics of evacuating a family with children, elderly family members, and pets during a disaster suggest that planning has an important role, as does ensuring that all members of the community have access to a means to evacuate when ordered to do so.

An unengaged and unprepared population is at a disadvantage when disaster strikes. It is valuable to explore the different experience that the island nation of Cuba has had with respect to risk communications, public preparedness, and disaster-related morbidity and mortality, for there are likely practices and 
behaviors that would serve us well in the United States. The size, intensity, and frequency of hurricanes that seasonally threaten Cuba are similar to those that affect the southeastern United States. What are very different are the outcomes that Cuba has been able to attain. For Hurricane Ivan, nearly 2 million were evacuated with no fatalities compared with 39 in Grenada, 25 in the United States, 17 in Jamaica, 4 in the Dominican Republic, 3 in Venezuela, 2 in the Cayman Islands, and 1 each in Tobago and Barbados [6,7]. Cuba has drastically reduced the number of storm-related deaths and injuries over the last few decades by promoting a system of citizen preparedness and involvement that starts in elementary school and includes mandatory civil defense training for adults. Furthermore, it has been done without a vast expenditure of funds. Children understand the basic concept of risk from hurricanes at an early age, and use this as a foundation for learning such skills as first aid and storm preparedness. Annual government-sponsored nationwide hurricane drills provide all citizens with the opportunity to test their family and community emergency plans before there is a crisis, and there is near complete buy-in to the benefits of this preparation.

There is also widespread cooperation among the population, the Cuban Red Cross, the civil defense authorities, the military, the government, and the broadcast media. When a hurricane does threaten, the citizens become extremely engaged in the potential threat and follow the storm's progress closely by television and radio. When authorities order an evacuation, it is undertaken promptly, efficiently, and decisively, with communities ensuring that those who need special assistance receive it. Because the actions of the community are rehearsed annually and are familiar, it is possible to efficiently evacuate and shelter many hundreds of thousands of citizens in short order when necessary. Although it would be naïve to think that the practices of a socialist society could be directly translated into a system that could operate well in the United States, the concept of engaging the public and practicing emergency procedures is an effective, but hardly a foreign, one. Indeed it is a system that has worked well for fire safety for generations in the United States. The ubiquitous fire drill at school, work, and home emphasizes that a behavior that is practiced is a behavior more likely to be used in a crisis. Box 1 lists guidelines in planning for a disaster and evacuation.

\section{Decision-making}

The issue of communicating risk and influencing public action is complex. Many who stayed behind in New Orleans during Hurricane Katrina may have felt that their lives, pets, and property would be better served by remaining at home rather than evacuating. Others certainly felt that the threat was not severe enough to merit the inconvenience, expense, and inherent risk of taking part in a mass evacuation. Still others may have felt that they had no place to go, and did not feel safe moving into a shelter. The track of a hurricane is difficult to predict at the time when the evacuation of a region needs to begin, typically 30 to 50 hours or more before the onset 


\section{Box 1: Lessons learned: planning for disaster and evacuation}

Ensure that all family members know of an out-of-area contact they can call. Teach children their phone numbers and address as early as possible.

Provide children with an emergency contact information card and have them keep it with them at all times.

Put together a supply kit of practical emergency equipment that may be needed in a disaster, and remember that it may need to be portable. Essentials include water, food, shelter, and essential medications. Include a recent photo of your children.

Discuss an emergency plan with all members of the family before there is an emergency. This plan should include actions for family members if they not at home when an emergency occurs.

Practice your emergency plan regularly. How will your family stay warm, find water, stay safe, and obtain emergency information during a variety of emergencies?

Promote and enable a culture of preparedness. Countries with mandatory, routine community disaster drills are capable of responding to disasters with fewer injuries and fatalities because people are familiar what they are supposed to do.

Remember that routine emergency services, such as 911 , likely will not be available during a disaster.

If an evacuation becomes necessary, consider writing essential information about your child on his or her arm with a permanent marker in case you become separated.

Include family pets in emergency planning. They may not be able to accompany the family during evacuation or be allowed in shelters.

of predicted damaging winds. As a result, many inhabitants of the Gulf Coast had years or decades of experience with "false alarm" warnings and evacuations, and a subsequent perception of low individual vulnerability to the effects of a storm. Despite unprecented warnings from the National Weather Service and the mayor prior to Hurricane Katrina, many still chose or were forced to stay behind when an evacuation order was issued for the city of New Orleans. There was overdependence by the city on an outdated emergency plan and an overreliance on the anticipated use of personal vehicles for evacuation when nearly 1 in 10 citizens did not have access to one. As a result, some individuals were not physically capable of evacuating in their own vehicles and the city could not make up for this incapacity with public transportation. Similarly, during Hurricane Rita, authorities underestimated the volume of vehicle traffic during the evacuation of the Houston area, resulting in massive congestion and fuel shortages. In Katrina, some state and federal assets were not called upon in a timely manner, and persistent bureaucracy was a steep barrier to many of the out-of-state personnel who wanted to assist. Box 2 lists guidelines related to disaster preparations and decision-making. 


\section{Box 2: Lessons learned: guidelines for being well prepared and making good decisions}

Individuals and their families have a duty to make responsible decisions, using the best information available. Children are dependent upon the good decisionmaking of their caregivers and should be subjected to the lowest amount of risk possible.

Consistently honest communication with the public regarding projected risk is likely a useful approach in the long term.

Risk assessment is a vital part of emergency preparedness at the personal and governmental level, and it should guide the development of response and recovery plans.

Families and communities should engage their local governments to share important disaster preparedness information.

Communities can play an active role in promoting their own readiness for emergencies through volunteerism, role modeling, and activism.

Children should be encouraged to be active participants in their family disaster planning and know their roles during an emergency. Practice with children essential basic lifesaving skills, such as home fire safety, first aid, and water safety, and review specifics of the family disaster plan.

\section{Obtaining shelter}

The mass movement of hundreds of thousands of hurricane victims before, during, and after Katrina placed an enormous burden upon the survivors as well as the agencies and private individuals who assisted with sheltering. The Federal Emergency Management Agency (FEMA) reported nearly 200,000 adults and children were in public shelters, with an unknown number staying in motels, camping, or living with others. The quantity of stormrelated "internally displaced persons" who are still living away from their previous home on the Gulf Coast has been cited at 1 million or more $[8,9]$. As mentioned above, an estimated 25,000 persons sheltered initially at the Louisiana Superdome, with up to 20,000 at the nearby New Orleans Convention Center. This situation was partially a result of the inability of the city to coordinate public transportation out of the area for those who did not have a vehicle. While there is no information about the number of children who sheltered in both the Superdome and the Convention Center, the number can be estimated from a survey of those survivors who were in the Houston Astrodome. Many were initially sheltered at the Superdome or the Convention Center. One third of the adults surveyed report having a child with them, which would suggest a minimum of approximately 15,000 children between the two refuges of last resort in New Orleans [10].

Children in the shelter environment pose special challenges because of their typically curious and active behavior. These challenges can include those related to safety and security, hygiene, health maintenance, and disease prevention. 
Disaster survivors frequently arrive at a shelter with few belongings. Frequently, items such as personal medications, personal hygiene supplies, and adequate food, water, and clothing are left behind. Hurricane Katrina was no exception, and many children arriving at shelters found themselves in an environment that could not support them with adequate water, nutrition, diapers, formula, or prescription medications, especially at first. As a result, it was not uncommon for hygiene conditions to rapidly deteriorate-a situation made worse by ineffective or nonexistent hand-washing facilities. Children are an important variable with regards to the spread of disease in a large communal living environment, such as a shelter. Because of their hand-to-mouth activity and close contact with other people and objects, it is thought that children are at a higher risk of acquiring respiratory and gastrointestinal diseases under these conditions. Additionally, because of their mobile and social nature, children are probably more efficient than adults at spreading certain diseases in this environment, which is similar to that of a shelter, such as a school or daycare center, where children will naturally congregate. Several shelters, including the massive Houston Astrodome, were affected by outbreaks of gastrointestinal disease, including Norovirus and presumed dysentery, although it is yet unclear the specific role that children played in these particular outbreaks, if any.

For a number of reasons, many emergency shelters are inherently unsafe or poor environments for children. For instance, there is no assurance of childproofing of medications and dangerous items that may be accessible. The supervision of children in this situation can be difficult at best. At the Louisiana Superdome, widespread rumors of child assault and rape contributed to a climate of fear, vulnerability, and stress. In some cases, pets were admitted to shelters because they accompanied the owners during evacuation, posing an additional risk. The stress of sudden dislocation, danger, and disorientation can be extremely challenging for children and their families.

Infants and children are more vulnerable to an interruption in the availability of essential supplies, such as water and nutrition. Problems facing those who were evacuated from New Orleans included a shortage of infant formula and bottles to deliver it. There was great concern about the need to maintain health prevention in the pediatric shelter population after the storm. Shelter managers and medical personnel were concerned about an inability to deliver important treatments, such as tetanus prophylaxis and antibiotics for those injured or exposed to flood water. There were also concerns about potential epidemics of childhood diseases, such as measles, pertussis, and chicken pox, as well as hepatitis A for those exposed to floodwaters.

As with planning for evacuation, planning for shelter is an essential component in the continuum of disaster preparedness. As discussed above, an overreliance on authorities or the American Red Cross (a nongovernmental agency responsible for coordinating mass care services) to completely provide for the essentials of food, water, shelter, and family emergency needs, such as 
medications, can be problematic. Much of the work of operating a shelter involves assisting those who have not prepared adequately to evacuate. If and when first aid stations are set up at a shelter, the top complaint is typically forgotten medications, an issue that can be time-consuming, if not impossible, to resolve. Forgotten or lost eyeglasses or contacts is the fourth most common chief medical complaint of evacuees, after physical complaints for gastrointestinal or respiratory symptoms.

From the provider standpoint, the experience with Hurricane Katrina revealed a gross underestimate of the basic needs of the sheltered population, especially in the initial stages of the response. In some cases, there were extensive specialized emergency supplies but a drastic shortage of the basics that are important for caring for children, such as formula, diapers, baby wipes, soap, and hand sanitizer. Compounding this situation, the resupply of these consumable items was at times impossible because of a host of logistical barriers. Another issue was the custody and care of children who were lost or unattended. Box 3 lists issues to keep in mind regarding shelter during a disaster.

Children with chronic and special health care needs

The care of children with special health care needs (CSHCN) during disasters is a topic that has come to the forefront after Katrina. Inasmuch as children are an underrepresented minority when it comes to disaster preparedness, CSHCN suffered even more disproportionately during the mass evacuations in the Gulf Coast. Because they depend on dedicated medical equipment, specialized medications, or their "medical home" of providers and specialists, children and adults with chronic health care needs can be especially vulnerable if preparations for disaster are inadequate.

\section{Box 3: Lessons learned: issues to keep in mind regarding shelter}

Do not assume that an emergency shelter will provide food, water, medication or eyeglass replacement, and hygiene items. These should be part of a family's emergency supplies and brought along during evacuation and sheltering.

Children play a unique role in the shelter environment with their ability to both spread and contract diseases, and proper hand-washing may not be possible. Waterless hand sanitizer may be a valuable item to bring along.

The shelter environment can be a dangerous place for children. They need to be closely supervised.

Children may be difficult to supervise in a shelter. Consider bringing something to keep them occupied.

Shelter managers should have a plan to reestablish pediatric health care as soon as possible, with a focus on screening for disease and ensuring that postdisaster immunizations can be delivered if needed.

Shelter managers in their planning should recognize the high demand for infantcare supplies, such as baby formula and diapers. 
The prevalence and distribution of CSHCN is larger than one might expect, which recently led to disaster planning oversights that had serious repercussions. Approximately 13\% of children are identified as CSHCN. The number of families who self-identify as having a family member who is CSHCN is $20 \%$ [11]. There is little variability across socio-economic descriptors. As medical technology and home care becomes more advanced, an increasing number of CSHCN who previously lived at a specialized care facility are now in the home.

The conditions that define a child as a CSHCN include, in the order of prevalence, (1) a need for specialized prescription medications $(75 \%)$; (2) a need for increased medical care $(46 \%)$; (3) a need for emotional, behavioral, or developmental services $(29 \%)$; (4) a limitation of activities (21\%); and (5) a requirement for specialized therapies (17\%) [11]. More than one of these descriptors may apply to many CSHCN. Each of these categories presents a unique vulnerability to the child required to break routine and undergo evacuation or emergency sheltering.

\section{Separation from specialized equipment}

The type of equipment that a CSHCN may depend on ranges from the assistive (motorized wheelchair) to the life-sustaining (home ventilator). In the inevitable crowded rush to evacuate before, during, and after a disaster, it is not uncommon for the decision to be made to separate a patient from his or her equipment due to time or space considerations. As New Orleans was evacuated during Katrina, devices that were not life-sustaining were often left behind under the assumption that a substitute could be acquired at the patient's ultimate destination. At the Louis Armstrong Airport medical waystation outside of New Orleans, evacuating survivors with nonacute medical needs were categorized as either able to walk to a commercial aircraft, or they were placed on military stretchers or in a wheelchair to await specialized military medical evacuation. Few accommodations were made for durable medical equipment that was not small and portable. There were limited options for those who required specialized medicines that were not in the government stockpile of basic pharmaceuticals, and options quickly ran out for patients who needed dialysis in the short term. In addition to the impact on health and life, this posed an unimaginable inconvenience to the patient, for whom the specialized equipment was a part of their identity as much as a technical means for them to care for themselves once they arrived at a shelter.

\section{Separation from specialized care}

Evacuation places a special burden on those who frequently visit clinics, rely on home nursing services, or otherwise depend on outside resources. Such resources are likely unavailable or reduced during a disaster, whether an evacuation occurs or not. Without adequate planning, the conditions of patients who are medically complicated are at an extreme risk of deteriorating if disaster has an impact on daily routine or if there is a loss of essential services, such as 
electricity or supply delivery. As discussed above, a basic shelter will probably not have any specialized medical supplies or staffing with the knowledge to properly care for a complicated CSHCN. There will likely be limited accommodations for those with sensory impairment.

As a result, specialized medical shelters have been developed in some areas to address the care needs of both children and adults with special health care requirements. These may be separate facilities or they may exist within a large general shelter for the public. With adequate planning and enough lead time, it may also be possible to relocate a CSHCN directly to a medical facility outside the affected region. Proper identification of the systems that will be expected to relocate and care for a CSHCN is a vital part of preparedness that must be done ahead of time. The child's "medical home" caregiver has a special responsibility to incorporate disaster planning into the overall care plan for the CSHCN.

When a CSHCN is relocated away from his or her medical home, the child may pose an extreme diagnostic challenge to medical providers, who may well be overwhelmed with medical responsibilities and who may not be pediatric specialists. Regardless of the diagnosis, it is helpful for a family emergency kit to contain an updated copy of an emergency information form for a patient with special health care needs (Appendix A). This document is created by the caregiver who knows the patient best, and it will provide invaluable guidance to reestablishing routine or emergency medical care in another location. If special medications are an important part of the child's routine, this must be accounted for during disaster planning. Medications that require refrigeration and frequent resupply will pose a special, but not insurmountable, challenge.

In some cases, such as Hurricane Katrina, the impact of the storm upon the health care facilities destroyed the permanent medical records of many patients, some of whom were complicated CSHCN. This has the potential to set back the care of the child greatly. In addition to the emergency form, it is important to discuss with the child's primary care provider how this information is backed up. It may be worthwhile to have a redundant copy stored in a safe location at home. From the perspective of a health care system, it is vital for future operation to be able to re-create any data that is destroyed during a disaster. Having electronic medical records that are backed up at multiple locations is a valuable concept and in all parties' best interests. Box 4 lists issues and concerns related to accommodating children with special health care needs during a disaster.

\section{Mental health response}

The scope of pediatric mental health disorders after disaster

There is extensive literature on the psychological impact of disasters on both children and adults. This literature covers a wide range of events, such as natural and technologic disasters. This section reviews some of the findings describing the psychological impact of disasters, both natural and human-caused on children. With this as background, the authors present new data gathered by the Children's Health Fund and the National Center for Disaster Preparedness on the mental health consequences of the terrorist attacks of September 11, 


\section{Box 4: Lessons learned: accommodating children with special health care needs}

The prevalence of children with special health care needs is approximately one in eight.

The prevalence of households who self-define as having a CSHCN is one in five.

A range of conditions may lead to a definition of $\mathrm{CSHCN}$. These include a dependence upon prescription pharmaceuticals, a need for an increased level of care, the need for emotional or behavioral services, a limitation of activities, and a requirement for special therapies.

The separation of medical or adaptive equipment from a dependent patient has significant repercussions and should be avoided wherever possible.

Most shelters will not have the capacity to care for complex CSHCN.

Some specialized medical shelters have been established and may be freestanding or integrated into existing general shelters

Medical information sharing is essential when a child is removed from his or her medical home. The use of an emergency medical information form should be encouraged to optimize the care of the child by unfamiliar providers.

The loss of medical records in a disaster can have a significant impact upon both patients and the provider. Establishing redundant copies is advisable.

Planning ahead for the disaster-time care of a CSHCN is vital. The child's primary care provider should be actively involved in developing a preparedness plan for the child and his or her family.

2001, and summarize findings from recent survey research following the extensive damage and forced relocation of families in Louisiana and Mississippi after Hurricanes Katrina and Rita, and the flooding in New Orleans subsequent to the breach of the levies there.

Analyses of the responses to past disasters demonstrate that psychological reactions in children do not necessarily follow a routine pattern or match the presentation of a similar condition in an adult. They can be delayed, complex, and long-lasting. For example, focusing on natural disaster in the United States, Shaw and colleagues [12] found that $70 \%$ of the school-age children reevaluated 21 months after exposure to Hurricane Andrew continued to exhibit moderate to severe posttraumatic stress symptoms. Two years after a dam break and flood, approximately 37\% of the exposed children and adolescents still had a probable diagnosis of posttraumatic stress disorder (PTSD) [13]. Outpatient mental health use increased to a statistically significant degree in the first year after Hurricane Floyd made landfall in North Carolina in 1999 [14]. A failure to provide mental health interventions following exposure to the 1988 Spitak earthquake in Armenia was associated with PTSD and depression in exposed and untreated adolescents [15]. Conversely, school-based mental health screening and targeted psychosocial intervention proved effective in identifying children with posttraumatic stress reactions and reducing their severity and impact following Hurricane Iniki in 1992 [16]. 
The separation of children from parents as well as parental stress reactions emerged as risk factors for protracted child psychological reactions. McFarlane [17] found that 26 months after exposure to an Australian wildland fire, one third of the children studied continued to present significant posttraumatic stress symptoms. It was reported that separation from parents in the immediate aftermath of the fire, maternal preoccupation with disaster, and the altered family dynamics were more important determinants of continuing symptomatology than the child's degree of first-hand exposure to the threat. These findings foreshadow some of the risks associated with the mass evacuation and relocation of children and families following Hurricane Katrina.

A substantial body of literature describes the mental health impact on children of the 1995 bombing of the Alfred P. Murrah Federal Building in Oklahoma City. Investigators found that more than $40 \%$ of regional middle and high school students knew someone who had been injured and more than one third knew someone who had died in the explosion. Besides the widespread first-degree contact with loss around the event, PTSD symptoms were associated with both direct exposure and with watching television reports of the bombing. Two thirds (67\%) reported worrying about their own and their family's safety [18]. These studies explore the role that mass media likely plays in the development of posttraumatic stress symptoms. Symptoms being manifested in locales geographically distant from the bombing are likely due to this effect [19-22]. Based on the Oklahoma City experience, it was recommended that child and adolescent television viewing of terrorist events be monitored and restricted, but this has proven difficult.

\section{Child reactions to two megadisasters: September 11, 2001, and Hurricane Katrina}

Ample experience from prior events could have predicted the widespread and long-standing impact that the terror attacks of $9 / 11$ and the flooding and evacuation following the landfall of Hurricane Katrina had and are continuing to exert upon children.

New York City, September 11, 2001, terrorist attacks. The Children's Health Fund and National Center for Disaster Preparedness at Columbia University, working with Marist College Institute for Public Opinion, developed and implemented surveys of child and family reactions to the events of 9/11 throughout 2002 and 2003, with representative New York City and national samples consistent with US Census Bureau data. Psychological reactions of New York City children were ascertained by interviewing parents about new concerns and new symptoms. It was immediately appreciated that in the first year after 9/11, reactions were geographically dispersed throughout New York City rather than concentrated or confined to those directly impacted; there was no psychological ground zero. The most pervasive reactions were concern about safety and fear of another attack, at $45 \%$ and $42 \%$ respectively 1 year after 9/11. The most stable symptomatic reaction was somatic complaints (headache, stomachache), reported by $15 \%$ of parents 3 weeks after 
$9 / 11$. Somatic complaints affected $16 \%$ of city children by the end of the first year and the same percentage 2 years post-9/11. This finding has implications for pediatricians and other health care providers, since these "subclinical" physical complaints may be indicative of posttraumatic stress reactions. Detailed results are included Table 1.

As an indicator of the need for mental health assessment and intervention, positive responses on these surveys were aggregated for children reported to have had four or more concerns or symptoms. Three weeks after $9 / 11,36 \%$ of children reported multiple psychological reactions, declining only to $34 \%$ at 6 months and $29 \%$ at 1 year. Two years after the attacks, this figure had only declined to $23 \%$, nearly one in four New York City children still exhibiting multiple reactions. These data suggest that posttraumatic stress reactions are likely to be protracted, at least without appropriate intervention. A review of the geographic distribution of children with multiple concerns and symptoms reveals that the highest rates were in the boroughs with the lowest income and highest proportion of racial-ethnic minority diversity with $32 \%$ in the Bronx and 31\% in Brooklyn affected. This is in contrast to the $26 \%$ rate among children residing in Manhattan, which was the wealthiest borough and the location of the World Trade Center, where the attack took place.

In the iteration of the survey 2 years after $9 / 11$, questions regarding parental reactions to the terrorist attacks and prior exposures to trauma within the family were added. Child reactions were analyzed for associations with parent reactions and prior stressors, and a positive correlation was apparent. Children with at least one post-9/11 concern were significantly more likely to have parents with at least one post-9/11 symptom. Fifty-two percent of children with multiple concerns and symptoms had a parent who reported being more impatient and irritable compared with $8 \%$ of children with no reactions and $16 \%$ with one to three reactions. Sixty-two percent of children with four or more

Table 1

Child reactions in New York City to the terrorist attacks throughout the first year post-9/1 1

\begin{tabular}{llll}
$\begin{array}{l}\text { Concern or } \\
\text { symptom }\end{array}$ & $\begin{array}{l}3 \text { weeks post-9/11 } \\
\text { (October 2001) }\end{array}$ & $\begin{array}{l}6 \text { months post-9/11 } \\
\text { (March 2002) }\end{array}$ & $\begin{array}{l}1 \text { year post-9/11 } \\
\text { (August 2001) }\end{array}$ \\
\hline $\begin{array}{c}\text { Concern about own } \\
\text { and family safety }\end{array}$ & $52 \%$ & $52 \%$ & $45 \%$ \\
$\begin{array}{c}\text { Fear of another } \\
\text { terrorist attack }\end{array}$ & $52 \%$ & $47 \%$ & $42 \%$ \\
$\begin{array}{c}\text { Nightmares, sleep } \\
\quad \text { disturbance }\end{array}$ & $20 \%$ & $17 \%$ & $17 \%$ \\
$\begin{array}{c}\text { Anxiety, } \\
\quad \text { distractibility }\end{array}$ & $39 \%$ & $38 \%$ & $30 \%$ \\
$\begin{array}{c}\text { Depression, } \\
\text { sadness, crying }\end{array}$ & $29 \%$ & $21 \%$ & $16 \%$ \\
$\begin{array}{c}\text { Somatic complaints: } \\
\text { stomachache, }\end{array}$ & $15 \%$ & $16 \%$ & $16 \%$ \\
headache & & & \\
\hline
\end{tabular}


concerns and symptoms had a parent who reported being sad or depressed, compared with $14 \%$ with no reactions and $26 \%$ with one to three reactions.

The most common child reaction 2 years post- $9 / 11$ remained concern about safety, affecting $42 \%$ of the city's children. All (100\%) children with one or more complaints reported having this concern as one of the multiple issues. Children with concern about their own and their family's safety were significantly more likely to be fearful of another terrorist attack than those who did not have this concern.

By the end of the 2003, a profile of children with the greatest need for mental health intervention became apparent, with $67 \%$ of these children reported as depressed, sad, or prone to crying, and $87 \%$ being distracted, anxious, or nervous. Almost half $(48 \%)$ showed regressive behavior, which included being clingy and attention-seeking.

In terms of race and ethnicity, the highest rate of posttraumatic distress was among Hispanic children, among whom 32\% had multiple concerns and symptoms, compared with $22 \%$ of black children and $15 \%$ of white children. Poverty was also a factor. Among families with incomes below $\$ 50,000,28 \%$ of children displayed multiple concerns and reactions compared with $17 \%$ among families with income above $\$ 50,000$. In New York's poorest borough, the Bronx, 26\% of children had multiple concerns and symptoms and only $27 \%$ had no reactions at all. In Manhattan, 15\% had multiple concerns and symptoms while nearly half $(48 \%)$ had no post-9/11 reactions. These results are consistent with findings that low income is a risk factor for posttraumatic stress reactions following a disaster or terrorist attack [23,24].

Prior exposure to trauma emerged as a factor in post-9/11 reactions. One fourth $(25 \%)$ of children with multiple concerns and symptoms had experienced some prior trauma, such as being a victim of or a witness to violent crime, or being in a serious accident, compared with 18\% of families of children with one to three reactions and $16 \%$ of families of children with no reported reactions.

The key child symptom questions asked in New York City were then repeated with a representative national sample. The degree to which the psychological impact of a megadisaster is experienced nationwide is reflected in these results 2 years after the terrorist attacks of 9/11. About one child in five nationally $(21 \%)$ had increased concern about safety and was fearful of another terrorist attack; $13 \%$ were reported to be demonstrating a qualitative increase in regressive behavior; 12\% anxiety; 9\% somatic symptoms; and 5\% depression and sadness. These children were evenly distributed among the regions of the country. However, racial-ethnic and income disparities were marked. Twenty-four percent of Hispanic children had multiple reactions, compared with $12 \%$ black and $7 \%$ white. The percentage of children with multiple reactions in families with incomes below $\$ 50,000$ was $50 \%$ higher than in families with incomes above $\$ 50,000$ (12\% versus $8 \%$ respectively).

Hurricane Katrina and the Gulf Coast. Before the hurricanes, Louisiana and Mississippi vied for the nation's highest poverty rates, highest percentage of 
uninsured children, and worst child health indicators [25,26]. These everyday social and public health challenges suggest that the region was poorly positioned at a baseline to respond to a surge in acute medical and mental health need, which was demonstrated in 2005.

Federal survey data from Katrina evacuees sheltered in San Antonio several weeks after the hurricane found that $42 \%$ of evacuee households had at least one member with a chronic health condition, $28 \%$ had at least one member with a physical or mental disability, and 20\% reported a current need for mental health intervention for at least one member [27]. These high rates of chronic conditions and mental health needs were subsequently corroborated in survey research done by Columbia University's National Center for Disaster Preparedness with families living in temporary FEMA-subsidized housing, typically mobile-home-style trailers. In common with earlier survey data of adult Katrina evacuees in Houston [10], the families in FEMA housing in both Louisiana and Mississippi were disproportionately low-income and African-American. Abramson and Garfield [28,29] observed that low-income families making $<\$ 10,000 / y$ were the hardest hit economically by the hurricane, with $53 \%$ losing all source of income (compared with 15\% for families with income $>\$ 20,000 / y)$.

One year after Katrina, more than half of caregivers at relocation sites in Mississippi reported that at least one of their children had new mental health concerns that emerged after the hurricanes. This is an even higher rate than was reported with similar methodology in FEMA relocation sites in Louisiana 6 months after the disaster, strongly suggesting that mental health issues after a megadisaster continue to emerge over time. In Mississippi, the rate of diagnosed child depression and anxiety disorders nearly quadrupled. Reported behavior problems doubled. It is likely that the pattern of overcrowded, occasionally dangerous, and transient living conditions that evacuees have been subjected to has contributed to the emergence of ongoing psychological problems [28].

In Mississippi, data following screening with a standardized instrument show that adult mental health symptoms are endemic amongst evacuees [30]. Sixty two percent of parents or caregivers reported symptoms of depression, anxiety, and/or posttraumatic stress disorders. This exceeds the screening results for Louisiana parents in FEMA shelters of $>50 \%$, again reinforcing evidence that postdisaster mental health problems emerge over time. Thirteen percent of parents reported that they were not able to cope day to day with the demands of caring for a child, an eightfold increase compared with pre-Katrina levels. Given the established degree to which parental coping mediates child reactions, this finding indicates an additional risk factor for problematic posttraumatic stress reactions in children.

Reports from school-based health centers throughout Louisiana indicate a greatly increased need for mental health services in the schools following Hurricane Katrina. Schools, especially those with a greater number or percentage of relocated students, reported relative increases in quarrels and 
fights among students $(73 \%$ and $67 \%$ of schools respectively), truancy (55\%), disruptive behavior (43\%), and sexual promiscuity $(31 \%)$. School personnel, including mental health professionals, reported a greatly increased need to provide case management and other concrete support services to parents [31].

Unmet postdisaster mental health needs. FEMA reports that it made available the highest level of funding (more than $\$ 150$ million) for postdisaster crisis counseling to New York following 9/11. Despite this, numerous sources indicate that there was and continues to be a mismatch between those in need and the services that could help them. A New York City study of the psychological impact and services received by children after the terrorist attacks of September 11 reported that approximately $18 \%$ of children had severe or very severe posttraumatic stress reactions, with only $27 \%$ of them receiving counseling or intervention services [32].

One year after $9 / 11$, only $13 \%$ of children in need had received mental health intervention. It was again observed that those with the most severe postdisaster responses (four or more post-9/11 reactions) were more likely to receive care. However, only $24 \%$ of these children received professional intervention, leaving three fourths untreated or potentially receiving inadequate services. Particularly noteworthy was the asymmetric distribution of, and access to, pediatric mental health resources. As noted previously, the need was greatest in the city's poorest borough, the Bronx, where only 9\% of children with multiple postdisaster reactions received mental health services compared with $22 \%$ in Manhattan.

The disparity between federal funding and actual receipt of mental health services by those in need is related in part to the narrow definition that the federal government has adopted for the term "crisis counseling." Restrictions on the allowable use of federal crisis counseling funding have impeded the ability of communities in New York and the Gulf Coast to rapidly ramp up their clinical mental health services after a disaster. Instead, "crisis counseling" has frequently consisted of simple mental health screening with little opportunity for necessary referral or follow-up, peer counseling, or the distribution of public service announcements. These broad and shallow interventions fall short of reacting to the acute need for true mental health services by patients with postdisaster depression, anxiety, and posttraumatic stress reactions. Children can become trapped in this process and, as we have seen, in many cases go un- or under-treated. In New York, data from the State Office of Mental Health show that 687,848 crisis counseling sessions were provided to 465,428 individuals, an average of approximately 1.5 sessions per user, most of whom were adults. These sessions were provided between September 2001 and December 2003 [33,34]. These data suggest that aggressive, longitudinal mental health interventions for children were poorly provided within the context of post- $9 / 11$ acute crisis counseling services. Additionally, most of the crisis counseling services funded with FEMA appropriations to New York City were terminated in August 2003. This in part accounts for the 
fact that only $\$ 137$ million of the $\$ 155$ million appropriation was spent and that services were terminated abruptly despite a documented ongoing need.

In recent years, evidence has been accumulating about the effectiveness of interventions for children's mental health disorders. Unfortunately, many knowledge and practice gaps still remain. The literature is limited regarding best-practice models and evidence-based treatments for poor, underserved, or ethnic-minority children impacted by extensive trauma, exactly the demographic that suffered the most during Katrina. More information about pediatric postdisaster symptomatology, as well as comorbidities, such as substance abuse, nonaccidental injury, and suicide, need further exploration. Initial research suggests that all may play a significant role in this environment.

Increasing the ability to recognize pediatric psychological problems should be a priority, as should bolstering the training to pediatricians, family doctors, mental health professionals, and other caregivers. There should be an emphasis on the importance of using traditional support systems, such as clergy, extended family, and community agencies, to supplement acute-care services. First responders should be oriented to the possible mental health issues impacting children postdisasters and become skilled in providing psychological first aid to families during the initial stages of a disaster response. Psychological first aid is a concept of promoting a sense of safety, calmness, connectedness, and self-efficacy during the evolving stages of a disaster, while at the same time offering assistance if it is needed. For those who will be monitoring children for symptoms, it is important to have a better understanding and practice with differential diagnosis in particular of such disorders as PTSD, depression, and those associated with adjustment, anxiety, and mood. The unique needs of children with preexisting mental health conditions also must be taken into account as they are the most vulnerable to subsequent problems and long-term effects.

For the appropriate mental health care of children and families after a disaster, a mechanism should be in place to provide for concrete needs, such as housing, food, and clothing assistance, as well as rapid return to a sense of routine, including school. This must be accompanied by screening for all and prompt aggressive therapy for mental health issues when indicated. Children and adolescents need to feel safe, have significant support, and possess a sense of hope and consistency to give them the best chance at recovering psychologically after a disaster. This has been a major shortfall in the Hurricane Katrina recovery efforts. Many families with children-the estimates are 125,000-continue to live in isolated and crowded FEMA housing or trailer parks. Up to one third of these children are suffering from a chronic illness, such as asthma, and only $50 \%$ of those who previously had routine medical care still do. Truancy is epidemic, and the quality of the education children are receiving is significantly affected by overcrowding and a progressively unsafe learning environment $[28,29]$.

Fostering a culture of resilience is an important way to empower individuals and families to recover their own lives after a disruption. In the postdisaster 
context, resilience is the ability to summon personal, relational, social, and cultural resources to handle adversity in a way that does not interfere with longterm functioning. Enhanced self-esteem and generalized efficacy, improved communication, better conflict mediation skills, and augmented capabilities in other domains of cognitive problem-solving are related to increased resilience. These can all be encouraged by engaging families and individuals in the disaster planning process at all levels, and by promoting the sense that they cannot depend entirely upon a system that may not have the capacity to care for them in a time of need.

On a policy level, it is essential that all disaster plans include extensive resources for assessing and treating child mental health issues and concerns and those of their caregivers. This should involve the integration and prioritization of psychosocial needs of children in the preparedness planning of federal, state, and regional/local government agencies. Similarly, communitybased agencies with a mission to promote wellness, foster resilience, and

\section{Box 5: Lessons learned: guidelines for pediatric mental health services}

Immediately after a disaster, pediatric mental health interventions should be practical and responsive to the concrete needs of children.

As soon as possible after a disaster, it is essential to create opportunities for children to express their feelings and concerns, to establish an environment where children feel safe, and to re-establish for children a sense of normalcy.

Providing psycho-education services and intervention where necessary to parents and caregivers is an essential component of early-stage relief that can have a significant impact on children.

Children obtain their sense of safety from adult cues. For children, a predictable routine (eg, school) and a consistent support system is important.

Direct losses may result in the development of more serious symptomatology, especially for children with previous exposure to loss or tragedy, or for those with preexisting mental illness.

Posttrauma symptoms often develop weeks or months after the "trigger" event.

Psychological problems may be inclusive or exclusive of PTSD. Such problems, which include depression, interpersonal problems, regression, stress, and an inability to trust and to feel safe and secure, may present right away or emerge over time. They may also be long-lasting.

There is no "ground zero" for the psychological effects of a disaster: The distance from the incident may not be directly related to the type or severity of symptoms.

Exposure to repetitive images or reports of a disaster on television or in other media may exacerbate the psychological response of a child and should be limited. The child should have an opportunity to discuss the meaning of those reports or images with an adult. 


\section{Box 6: Lessons learned: pediatric disaster mental health systems}

Failure to provide adequate pediatric postdisaster mental health services when needed may increase the number and severity of symptoms, such as PTSD and depression.

Children in families with a low income as well as members of racial or ethnic minority populations are at a disproportionate risk for experiencing new and multiple psychological symptoms and/or behavior problems after a disaster.

After a disaster, the ability of a family with children to cope with the day-to-day pressures of care may decrease significantly.

Many children in need of services in the postdisaster environment may not be receiving them. A high index of suspicion is prudent to monitor for depression or stress-related symptoms.

After a disaster, there may be increased incidents of substance abuse, child maltreatment, suicidal ideation, and completed suicides.

prepare families for disaster should be developed and funded. These agencies can focus on encouraging self-efficacy, better communication, and effective ways to involve all members of family in age, language, and culturally appropriate preparedness activities. Box 5 provides guidelines for pediatric mental health services during and following a disaster. Box 6 summarizes findings related to pediatric disaster mental health systems

\section{SUMMARY}

Many specific lessons were learned from recent megadisasters in the United States at the expense of children who suffered from a government and a citizenry that was desperately unprepared to respond to and recover from the disaster's short- and long-term effects. During the $9 / 11$ attacks, the nation learned a new sense of vulnerability as the specter of terrorism was delivered repeatedly to our collective consciousness. As this article has emphasized, children experienced significant and widespread psychological effects from this event, and many did not receive adequate treatment. Hurricane Katrina exploited the weaknesses of an already strained child mental health system and vividly demonstrated the liability of poor preparedness and inadequate communication by both families and governments. The impact of Katrina continues to affect many thousands of children over a year later, as the systems that were intended to care for them have largely moved on. Indeed, there was no mention of Hurricane Katrina, the Gulf Coast, or the storm's survivors in the 2007 State of the Union address by the President.

After 9/11 and the unprecedented federal spending that occurred to increase our nation's readiness, it is discouraging that the response to Hurricane Katrina fell so short of what had the potential to be the greatest disaster response and recovery story in the history of our nation. It is unlikely that further 


\section{Box 7: Lessons learned: national priorities for child disaster care}

Encourage a national culture of preparedness that engages the public in taking responsibility for some of its own care during a crisis. Draw from successful examples, such as the Cuban disaster readiness system, which teaches children the fundamentals of preparedness and resilience and how to apply these skills. A national disaster preparedness day to apply and evaluate response and recovery planning at all levels would send a strong message to families, communities, and businesses in the United States that this is time well spent.

Assure that the disaster planning agencies as well as the medical response and sheltering systems in the United States are better informed and empowered to address the special medical and psychological needs of children after a disaster.

Encourage primary care providers for children, especially those with special health care needs, to become involved in advocating for effective family disaster preparedness.

Significant attention needs to be paid to the wide-reaching and long-lasting effects of disasters on the mental health of children. Recent research-based evidence should drive major efforts to increase the availability of direct services after a significant event. A special focus is needed for children identified to be at the highest risk for debilitating psychological effects, such as those who are members of racial or ethnic minority groups and those in poor families.

uncontained expenditures will solve the problems that were exposed in the Gulf Coast. There is not a solution that money can buy. One need only look a few hundred miles south to the Cuban disaster response system to appreciate where some of our shortfalls lie. Cuba has succeeded where the United States has not in part because its citizens are participants in their own preparedness. They engage their children and their families in preparedness planning and they rely upon other members of their community to strengthen their ability to survive as individuals. The American mentality of "dial 911 in an emergency and wait for help" works only as long as there are enough resources to match the need. In a disaster, this approach has proven to be inadequate over and over again. In America, we are well positioned to be leaders in responding to the needs of children affected by disaster. The resources of our government and the resourcefulness of our people should offer much promise for the future. By analyzing our past shortfalls and taking practical steps to mitigate the existing barriers to preparedness, our children, we hope, will fare much better the next time a megadisaster strikes. Box 7 includes suggestions for national priorities for child disaster care.

\section{Acknowledgments}

We are grateful to Sarah Overholt at the Children's Health Fund for her assistance in the preparation of this document. 


\section{APPENDIX A. EMERGENCY INFORMATION FORM FOR CSHCN}

Form includes statement that document may be released with credit to the American College of Emergency Physicians and the American Academy of Pediatrics.

\section{Emergeney Information Form for Children With Special Needs}

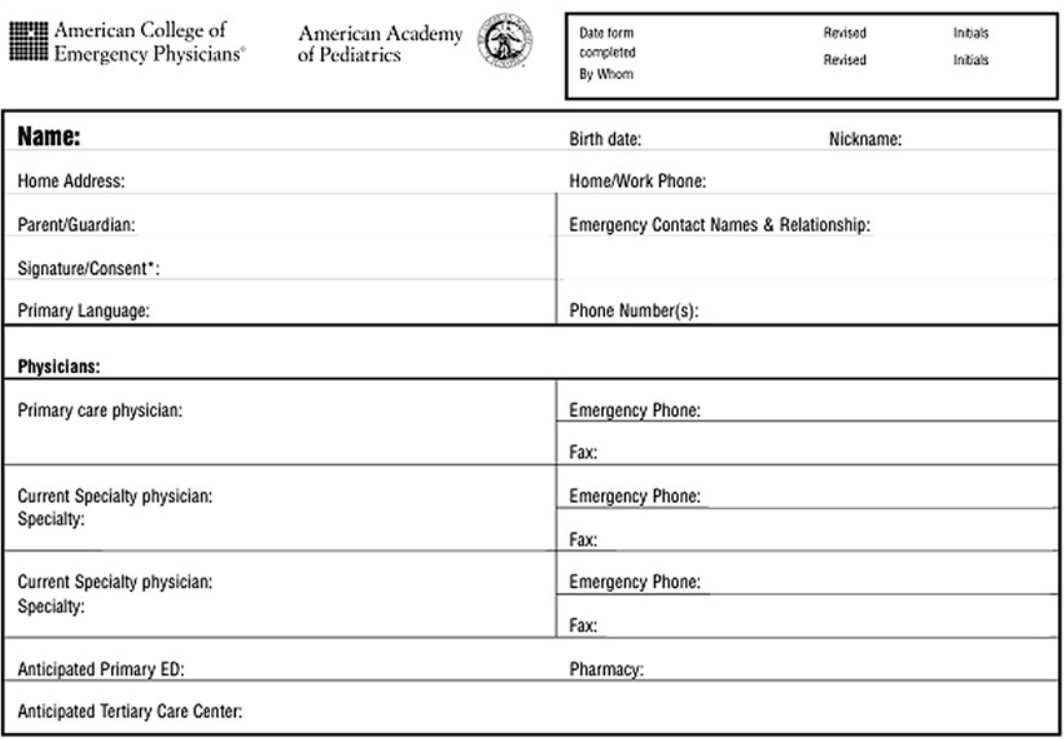

\begin{tabular}{|llll|}
\hline Diagnoses/Past Procedures/Physical Exam: & & & \\
\hline 1. & & Baseline physical findings: \\
\hline 2. & & & \\
\hline 3. & & Baseline vital signs: \\
\hline 4. & & \\
\hline Synopsis: & & \\
\hline & & \\
\hline & & \\
\hline
\end{tabular}

'Consent for relesse of this form to health care providers 

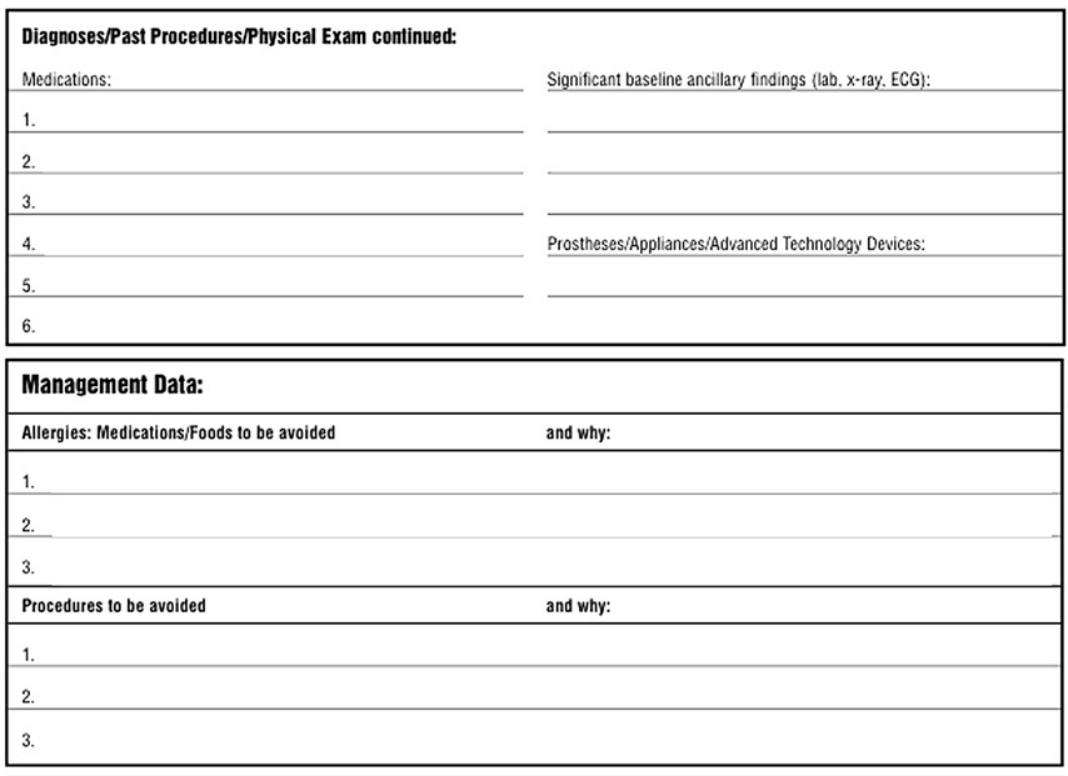

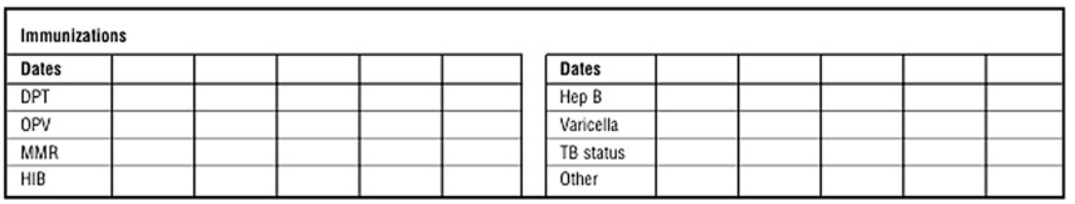

Antibiotic prophylaxis: Indication: Medication and dose:

\section{Common Presenting Problems/Findings With Specific Suggested Managements}

Problem

Suggested Diagnostic Studies

Treatment Considerations

Comments on child, tamily, or other specific medical issues:

\section{References}

[1] Redlener I. Americans at risk: why we are not prepared for magadisasters and what we can do now. New York: Alfred A. Knopf; 2006.

[2] Litman T. Lessons from Katrina and Rita: what major disasters can teach transportation planners? Journal of Transportation Engineering 2006;132:11-8.

[3] 20,000 shelter at Superdome. The Times-Picayune. 2005. Available at: http://www. timespicayune.com. Accessed February 4, 2007. 
[4] Osofski JD, Osofski H, Harris W. Katrina's children: social policy considerations for children in disasters. Social Policy Report 2007;21:3-18.

[5] Redlener I, Abramson D, Grant R, et al. Where the American public stands on terrorism, security, and disaster preparedness. Available at: www.ncdp.mailman.columbia.edu/files/ 2006_white_paper.pdf. Accessed February 3, 2007.

[6] Martin S. Can we learn from Cuba's lesson? St. Petersburg Times. September 9, 2005. Available at: http://www.sptimes.com/2005/09/09/Worldandnation/Can_we_learn_ from_Cub.html. Accessed May 30, 2007.

[7] Stewart S. National Hurricane Center tropical cyclone report: Hurricane lvan. Available at: http://www.nhc.noaa.gov/2004ivan.shtml. Accessed February 2, 2007.

[8] Global IDP Project. IDP Estimates. Available at: www.idpproject.org. Accessed October 6, 2005.

[9] Reuters. Katrina numbers illustrate storm's toll. Available at: www.alertnet.org. Accessed October 7, 2005.

[10] Brodie M, Weltzien E, Altman D, et al. Experiences of Hurricane Katrina evacuees in Houston shelters: implications for future planning. Am J Public Health 2006;96(8): 1402-8.

[1 1 1] U.S. Department of Health and Human Services. The National Survey of Children with Special Health Care Needs. Available at: http://wwwmchb.hrsa.gov/chscn/index.htm. Accessed February 2, 2007.

[12] Shaw JA, Applegate B, Schorr C. Twenty-one-month follow-up study of school-age children exposed to Hurricane Andrew. J Am Acad Child Adolesc Psychiatry 1996;35(3): 359-64.

[13] Green BL, Korol M, Grace MC, et al. Children and disaster: age, gender, and parental effects on PTSD symptoms. J Am Acad Child Adolesc Psychiatry 1991;30(6):945-51.

[14] Fried BJ, Domino ME, Shadle J. Use of mental health services after Hurricane Floyd in North Carolina. Psychiatr Serv 2005;56:1367-73.

[15] Goenjian AK, Walling D, Steinberg AM, et al. A prospective study of posttraumatic stress and depressive reactions among treated and untreated adolescents 5 years after a catastrophic disaster. Am J Psychiatry 2005;162:2302-8.

[16] Chemtob CM, Nakashima JP, Hamada RS. Psychosocial intervention for postdisaster trauma symptoms in elementary school children. Arch Pediatr Adolesc Med 2002;156: 211-6.

[17] McFarlane AC. Family functioning and overprotection following a natural disaster: the longitudinal effects of post-traumatic morbidity. Aust N Z J Psychiatry 1987;21(2): 210-8.

[18] Pfefferbaum B, Nixon SJ, Krug RS, et al. Clinical needs assessment of middle and high school students following the 1995 Oklahoma City bombing. Am J Psychiatry 1999; 156:1069-74.

[19] Pfefferbaum B, Seale TW, McDonald NB, et al. Posttraumatic stress two years after the Oklahoma City bombing in youths geographically distant from the explosion. Psychiatry 2000;63:358-70.

[20] Pfefferbaum B, Nixon SJ, Tivis RD, et al. Television exposure in children after a terrorist incident. Psychiatry 2001;64:202-11.

[21] Pfefferbaum B, Sconzo GM, Flynn BW, et al. Case finding and mental health services for children in the aftermath of the Oklahoma City bombing. J Behav Health Serv Res 2003;30:215-27.

[22] Pfefferbaum B, Seale TW, BrandtEN Jr, et al. Media exposure in children one hundred miles from a terrorist bombing. Ann Clin Psychiatry 2003;15:1-8.

[23] Ahern J, Galea S. Social context and depression after a disaster: The role of income inequality. J Epidemiol Community Health 2006;60:766-70.

[24] Weissman MM, Neria Y, Das A, et al. Gender differences in posttraumatic stress disorder among primary care patients after the World Trade Center attack of September 11, 2001. Gend Med 2005;2:76-87. 
[25] Annie E. Casey Foundation. Kids Count: state-level data online-Louisiana. Available at: http://www.aecf.org/kidscount/sld/profile_results.jsp? $r=26 \& ; d=1$. Accessed February 6, 2007.

[26] Annie E. Casey Foundation. Kids Count: state-level date online-Mississippi. Available at: http://www.aecf.org/kidscount/sld/profile_results.jsp? $r=26 \& ; d=1$. Accessed February 6, 2007.

[27] Centers for Disease Control. Rapid assessment of health needs and resettlement plans among Hurricane Katrina evacuees-San Antonio, Texas. Morbidity and Mortality Weekly Report 2005; 55: 242-44. Available at: http://www.cdc.gov/mmwr/preview/ $\mathrm{mmwrhtml} / \mathrm{mm} 5509 \mathrm{ab}$.htm. Accessed January 26, 2007.

[28] Abramson D, Garfield R. On the edge: responding to an emerging humanitarian crisis in Louisiana and Mississippi: urgent need for a health care "Marshall Plan." Available at: http://www.ncdp.mailman.columbia.edu/files/marshall_plan.pdf. Accessed January $31,2006$.

[29] Abramson D, Garfield R, Redlener I. The recovery divide: poverty and the widening gap among Mississippi children and families affected by Hurricane Katrina. Available at: http://www.ncdp.mailman.columbia.edu. Accessed February 5, 2007.

[30] The mental health component summary score of the MOS-SF 12 Version 2.

[31] Madrid P, Garfield R, Grant R. Mental health services in Lovisiana school-based health centers post-Hurricanes Katrina and Rita. Prof Psychol Res Pr, in press.

[32] Fairbrother G, Stuber J, Galea S, et al. Unmet need for counseling services by children in New York City after the September 11 th attacks on the World Trade Center: implications for pediatricians. Pediatrics 2004; 113(5):1367-74.

[33] Donahue SA, Covell NH, Foster M, et al. Demographic characteristics of individuals who received Project Liberty crisis counseling services. Psychiatr Serv 2006;57:1261-7.

[34] Donahue SA, Lanzara CB, Felton CJ, et al. Project Liberty: New York's crisis counseling program created in the aftermath of September 11, 2001. Psychiatr Serv 2006;57:1253-8. 